\title{
Genetics in primary care
}

Report on Workshop of EC Concerted Action on Genetics Services in Europe (CAGSE) in association with the Royal College of GP Spring Meeting, Blackpool, UK, 28 April 1995

The Royal College of GP Spring Meeting lasted three days with half of this time devoted to genetic topics. There were plenary talks by Walter Bodmer, Alex Markham, and Andrew Read and a well attended panel discussion on ethical issues arising from genetics. An EC Workshop on primary care genetics was organised as a satellite of the RCGP meeting. The success of this workshop led to an open conference on Primary Care Genetics at the Royal Society of Medicine in London on 18 November 1995 where the main points and conclusions were discussed by a large audience of general practitioners and others.

The workshop was organised because molecular genetics, clinical genetics, and rising public expectations are creating increasing demands on healthcare systems. It appears unlikely that geneticists alone will be able to cope with the volume of work generated. Primary care based healthcare systems are recognised to be economical while primary care teams, where they exist, have long term "guardianship" of patients' interests. Primary care must work in partnership with specialist genetics centres in the development of effective and cost effective population genetic services.

The workshop participants* were multidisciplinary including people from Britain, Germany, and The Netherlands working in primary care, multidisciplinary medical genetics, public health, and social sciences.

Rodney Harris described the EC Concerted Action on Genetic Services (CAGSE) in the context of the different health care systems, multilingual and multicultural societies of Europe. ${ }^{1}$ CAGSE is reviewing and recommending improvements in genetics, including the involvement of primary care. The partnerst in CAGSE are leading medical geneticists, working with sociologists and others to produce for each country a detailed report using a standard

* Dr Joan Austoker, Ms Tara Clancy, Dr Gareth Evans, Dr Godfrey Fowler OBE, Dr Hilary Harris, Prof Rodney Harris, Mr A Kent, Dr T Lancaster, Dr Mairi Levitt, Prof Bernadett Modell, Dr Michael Modell, Prof Martinus Niermeijer, Prof Irma Nippert, Prof Peter Nippert, Dr Mike Powell, Dr Nadeem Qureshi, Prof Sandy Raeburn, Prof Martin Roland, Dr Darren Shickle, Dr Jeremy Fenby-Taylor, Dr Paula Williamson.

† Rodney Harris (Chairman), Martinus Neirmeijer (Co-chairman for north Europe), Giovanni Romeo (Co-chairman for south Europe), Lene Koch, Jean-François Mattei, Margareta Mikkelsen, Dirk Stemmerding.

$\ddagger$ Availability, access, life sustaining, conformity with state of art, non-harmful, effectiveness, and consumer satisfaction. framework of markers to evaluate the quality of seven dimensions $¥$ of genetic care, which have already been tested on overall health care in the French, German, UK, and US systems. ${ }^{2}$

Data collected so far show that genetics services in Europe vary greatly, particularly in the extent to which regional medical genetics centres are available, and staffed by trained clinicians and laboratory scientists. ${ }^{3}$ There are also great differences in the availability of population and pregnancy screening for genetic disorders. The UK is unusual in having developed extensive pregnancy screening for neural tube defects and Down syndrome, and screening for carriers of cystic fibrosis (albeit patchy and mainly research based). In contrast the social and legal environments appear unfavourable to population genetic screening in The Netherlands and Germany, as described by Niermeijer and Nippert at the workshop.

\section{Primary care genetics}

There are very different degrees of development of primary care in the healthcare systems of Europe $^{4-7}$ The practicability of primary care genetics is linked to the structural characteristics of healthcare delivery system, especially the method of remuneration of doctors, particularly when this encourages overdiagnosis and treatment, rather than discussion and counselling. Where patients' choice of specialist is unconstrained by health service limits on resources, for example, in Germany, there seem to be few impediments to an expansion of genetic specialists other than the practicalities of training and resources.

Healthcare systems with highly developed primary care systems (for example, the UK) appear to offer many advantages to patients and to those at risk of genetic disorders ${ }^{8}$ and it was suggested by Sandy Raeburn that there is a natural partnership between primary care and medical genetics. Thus, in the UK, GPs are the points of first contact for most patients and filter referrals to specialists. However, more extensive roles for primary care in the provision of genetics services were discussed in the workshop. These included: (1) recognition of need, (2) appropriate referral to specialists, (3) continuing care of people and families with genetic problems, (4) timely counselling, (5) initiation 
of prenatal diagnosis and termination if requested, (6) education of patients.

The primary care team sees patients both by themselves and within their family framework, and can offer continuity of care, lifetime records, and a generalist approach to genetic disorders that affect all ages, all body systems, and multiple family members.

Pilot studies ${ }^{9}$ and contributions to the workshop by Hilary Harris, Fenby-Taylor, and Evans reported that in Britain with the help of genetic centres, primary care teams can successfully undertake counselling and genetic population screening. Primary care offers opportunities for targeted screening of high risk groups such as ethnic minority communities at risk of thalassaemia and sickle cell disease, as reported to the workshop by Nadeem Qureshi. Offer of screening in very early pregnancy, as shown by Hilary Harris in primary care, will allow prenatal diagnosis and termination of affected fetuses within the first trimester and after full counselling. Primary care involvement will be increasingly important as markers for Down syndrome move into the first trimester.

Obtaining consent before genetic screening is problematical and may be neglected as in some serum screening programmes for Down syndrome. Recent discussion ${ }^{10}$ has suggested the possibility of "generic consent". This would stress the common features of an increasing number of forms of antenatal screening and would avoid overloading patients with information. Could generic advice and consent also be obtained in primary care where the family is known to the doctor and the setting is familiar to the patient? This would reduce the need in the hospital antenatal clinic for potentially depressing discussions about fetal abnormality and termination.

The workshop discussed whether general practitioners can cope with genetics and several presentations showed untapped skills in primary care in the UK. However, in some countries primary care is not well developed and in the UK involvement in genetics may be slow because of current work practices and other constraints, including opposition from hospital specialists, insufficient time for genetic counselling, insufficient funds, and lack of training and knowledge, as reported by Fenby-Taylor. Identifying optimum genetics services will require clear definition of desired outcomes and these will be strongly influenced by the social structure and historic precedents in each European country. Health services research is needed to test various strategies for genetic services as discussed by Roland, Modell, Austoker, and others at the workshop.

\section{Conclusions}

Different arrangements for medical genetics services will be needed in countries with well developed primary care, compared with those where primary care is not well developed. In countries which do not have well developed primary care there may be uncontrolled increases in referrals to specialists and unacceptably long waiting lists in the absence of a major increase in numbers of specialists. Tara
Clancy reported how genetic nurses, genetic counsellors, nurse practitioners, midwives, and other non-medical staff can provide an economic supplement to specialists and link primary care with genetic centres. They are particularly capable of supervising the long term support of families with genetic problems especially if this support is backed by an adequate longitudinal family record system. However, Germany, for example, seems set on a purely specialist service and there are doubts that genetic workers (genetic nurses, etc) will be encouraged with important implications for equal job opportunities within the EU. Similarly, with the exception of the UK and Denmark, confidentiality laws may inhibit longitudinal family record systems. The role of Public Health Medicine was discussed by Darren Shickle who stressed the importance of epidemiology and properly organised population genetic screening.

Specialist genetic centres will remain the core of a genetic service but will be greatly augmented by collaboration with other services to provide comprehensive facilities. In the UK there is concern also at present because of government moves to devolve priority setting for genetics, including for rare disorders, to fund holding GPs, most of whom have fewer than 20000 patients on their lists. This has temporarily clouded the issue and in spite of the currently onerous work loads in general practice primary care is inevitably a partner in the provision of genetic services because of patients' expectations. GPs should be able to take a useful family history, recognise clues to increased genetic risk, be capable of relaying appropriate genetic information to patients, and above all to know how to obtain advice from genetic specialists.

It is currently impracticable and probably inappropriate for all existing general practitioners to be offered detailed training in medical genetics, but primary care teams would be greatly assisted by training packages and computerised guidelines on genetic problems, for example, familial breast and bowel cancer.

Specific genetic training should become part of the personal professional development of some established principals who are intent on developing special clinical interests and GP registrars should be exposed to genetics during vocational training programmes. Training in genetics could also become one of the clinical modules of the higher training in general practice. GP registrars are members of a generation that has grown up with computers and are well equipped to take advantages of new information technology.

A group was formed under the aegis of the Royal College of General Practitioners and the EC Concerted Action on Genetic Services in Europe with the support of the British Clinical Genetics Society and the European Society for Human Genetics to take forwards discussions on the role and training of primary care in the provision of genetics services.

We are grateful to Dr Lotte Newman (President of RCGP), Dr Clifford Kay, and Sir Donald Irvine for their support and advice, to Halina Dawson, NW Faculty Manager, RCGP for help in 
organising the workshop, and to Rona Mayall, Department of Medical Genetics, St Mary's Hospital, Manchester for secretarial support. Rodney Harris is grateful to the Wolfson Foundation for support which allowed the involvement of Hilary Harris and the establishment of the Primary Care Genetics Group.

\section{RODNEY HARRIS} HILARY HARRIS Central Manchester Healthcare Trust and Department of Medical Genetics, Manchester M13 OfH, UK

1 Harris R. Report of ESHG Satellite Meeting: EU Concerted Action on Genetic Services in Europe (CAGSE) Eur $\mathcal{F}$ Hum Genet 1994;2:300-3 (annex 7).

2 Feldbaum EG, Hughesman MA. Healthcare systems cost containment versus quality. Financial Times Management Report, 1993.
3 Harris R, Rhind J. The specialty of clinical genetics: European Society of Human Genetics survey. 7 Med Genet 993;30:147-52.

4 Starfield B. Primary care and health. A cross national comparison. $\mathcal{F} A M A$ 1991;266:2268-71.

5 Starfield B. Primary care. Concept, evaluation and policy. New York: OUP, 1992

6 Boerma WGW, de Jong FAJM, Mulder PH. Health care and general practice across Europe. Utrecht: Netherlands and general practice across Europe. Utrecht: Nethe

7 Fry J, Horder J. Primary health care in an international context. London: Nuffield Provincial Hospitals Trust, 1994

8 Harris R, Harris HJ. Primary care for patients at genetic risk: a priority for $\mathrm{EC}$ concerted action on genetics services. BMf 1995;311:579-80.

9 Harris H, Scotcher D, Hartley N, Wallace A, Craufurd D, Harris R. Cystic fibrosis carrier testing in early pregnancy by general practitioners. $B M \mathcal{F} 1993 ; 306: 1580-3$.

10 Elias S, Annas GJ. Generic consent for genetic screening. N Engl f Med 1994;330:1611-13. 